\title{
Medico-legal evaluation and trend of the different patterns of maxillofacial fractures concomitant with closed head injury in Upper Egypt: retrospective study
}

Doaa M. El Shehaby ${ }^{1 *}$ (D) Alsayed Magdi Alsayed Farahat ${ }^{2}$, Mohammed S. Shahine ${ }^{3}$ and Heba M. Mohammed ${ }^{4}$

\begin{abstract}
Background: Maxillofacial fractures are of great medico-legal implications because they are of common occurrence with other injuries, predominantly head injuries that might involve serious esthetic and functional problems, and so clinically described as consequential injuries. The aims were to assess the medico-legal aspects of maxillofacial fractured cases concomitant with closed head injury over a 6-year period (2011-2016) in the Trauma Unit of Assiut University Hospitals, Egypt, and to evaluate the demographic feature and the trend of different patterns of such fractures.
\end{abstract}

Patient and methods: A descriptive hospital-based study included all cases of maxillofacial fractures combined with closed head injury attending the Trauma Unit of Assiut University Hospitals in the period of January 2011 to December 2016.

Results: The study included 1221 cases, the percent of maxillofacial fractures with a closed head injury was 4\%, the age group 18-40 years was having the highest incidence, and mean age was $25.9 \pm 15.3$ years with male to female ratio of 7:1. Road traffic accidents were the main etiology of injury (69.7\%), followed by falls (15.1\%) and violent assaults (10.2\%) while firearm injuries were the last (5\%). Unintentional injuries were the commonest in $83.1 \%$ followed by homicidal (16.3\%); only 7 cases were due to suicidal attacks. The mandibular fracture was the commonest (49.7\%) followed by fracture maxilla (19.2\%), fracture zygoma (16.8\%), and lastly frontal bone and nasal fracture. The trend of maxillofacial fractures over the 6-year period tended to be increased with the highest number in 2011 (21.5\%) and the lowest in 2014 (13.3\%).

Conclusion: Maxillofacial fracture with a closed head injury in Upper Egypt is common in the middle age with male predominance. Road traffic accident is the main etiologic factor, and accidental trauma is the commonest manner. Mandibular fractures are the commonest pattern followed by fracture maxilla. Traumatic head injuries in cases of maxillofacial fractures were mild in about half of the cases. The trend of maxillofacial fractures over the 6year period of the study (2011-2016) tended to be increased with the highest number in 2011 and the lowest in 2014.

Keywords: Medico-legal, Maxillofacial , Fractures, Closed head injury, Trend, Egypt

\footnotetext{
*Correspondence: drdoaamoh@aun.edu.eg; drdoaamoh@yahoo.com

'Department of Forensic Medicine \& Clinical Toxicology, Faculty of Medicine,

Assiut University, Asyut 71515, Egypt

Full list of author information is available at the end of the article
} 


\section{Introduction}

Maxillofacial fractures are of special medico-legal implications as they are considered medico-legal cases and a part of poly-trauma conditions. Maxillofacial injuries are commonly encountered in the emergency medicine; most patients with these injuries have multisystem trauma that requires coordinated management between emergency physicians and surgical specialists in maxillofacial surgery, otolaryngology, plastic surgery, and general surgery (Delpachitra and Rahmel 2016). Maxillofacial fractures include fractures extending from the frontal bone down to the base of the skull and include fracture of the frontal bone, zygoma, maxilla, nasal bone, ethmoid, and mandible (Fama et al. 2017).

Trauma to the maxillofacial region mandates special attention as important sensory systems are contained within the face (e.g., vision, auditory, somatic sensation, gustatory, olfaction, and vestibular). Also, vital structures in the head and neck region are intimately associated (airway, blood vessels, and nerves). Lastly, the psychological impact of disfigurement can be devastating (Kloss et al. 2008). The maxillofacial fractured patient is a polytraumatized one that requires careful and regularly updated assessments and clears open communications with the surgeon. The preoperative reconstruction plan of functional areas is critically required to guide the physical, psychological, and social rehabilitation process. During surgery, monitoring, controlling, and documenting the patient's anesthetic course and any surgical emergencies are necessary. All of these legal goals reflect the quality of care fostering patient safety and will legally protect the surgeon as well (Parashar and Sharma 2013).

The basic traumatic head injury (THI) is an insult to the head due to an external mechanical force, possibly leading to a temporary or permanent impairment of cognitive, physical, and psychosocial functions, associated with a diminished or altered state of consciousness. There are two types of THI: closed head injury (or nonpenetrating) and open head injury (or penetrating) (Zandi and Hoseini 2013). Closed head injury (CHI) is the most common cause of traumatic brain injury. This brain injury is due to an external impact leading to a sudden violent motion but does not include a break in the skull. A concussion is the major consequence of closed head injuries followed by epidural hematoma, subdural hematoma, and intracerebral hemorrhage (Syed et al. 2007).

The etiology of maxillofacial fractures varies from one geographical region to another and even within the same region depending on the prevailing socio-economic, cultural, and environmental factors. The amount of force required to cause damage to the facial bones differs regionally; the supraorbital rim, the maxilla and the mandible (symphysis and angle), and the frontal bones require a high impact force to be damaged. A low impact force is all that is required to damage the zygoma and the nasal bone; high impact and low impact forces are defined as greater or lesser than 50 times the force of gravity (Motamedi 2003).

\section{Materials and methods Aim of the study}

- It is to assess maxillofacial fractured cases associated with closed head injury over a 6-year period (20112016) in the Trauma Unit of Assiut University Hospitals, Egypt.

- It is to evaluate the medico-legal aspects (cause, manner, patterns, and outcome), identify the sociodemographic background (age, sex, residence, occupation), and assess the trend of different patterns of such fractures.

\section{Study design and setting}

The study is a retrospective descriptive hospital-based study conducted in the Trauma Unit of Assiut University Hospitals (tertiary care hospital), Egypt. The Trauma Unit of Assiut University Hospitals is considered as the central unit of trauma in Upper Egypt, to which cases from all Upper Egypt and the Red Sea Governorates attend it.

\section{Study population}

The study included all cases of maxillofacial fractures combined with closed head injury attended the Trauma Unit of Assiut University Hospital during the period from 1 January 2011 to the end of December 2016.

\section{Exclusion criteria}

- Maxillofacial fracture cases with an open traumatic head injury as they already were transmitted to the Neurosurgery Department

- Patients admitted with isolated facial soft tissue injuries

- Neurosurgical interventions of previous injuries and deformities

- Patients discharged on their request before the examination

\section{Registered data}

- Socio-demographic data of cases: age, gender, residence, and occupation.

- Medico-legal aspects of cases: etiology, pattern, manner, and outcome of injuries. Fractures of the facial skeleton were classified into mandibular, maxillary, zygomatic, frontal bone fractures, naso- 
ethmoidal fractures, and multiple site fractures. Computerized tomography (CT) scan was the current imaging standard for evaluating a multitraumatized patient and used for identification of the fracture pattern and defining the type of traumatic head injury.

- Clinical profile of cases: the Glasgow Coma Scale (GCS) - patients are classified into three grades: mild $(\mathrm{GCS}=13-15)$, moderate $(\mathrm{GCS}=9-12)$, and severe $(\mathrm{GCS}=3-8)$. Types of treatment (surgical or conservative), treatment modalities (arch bar or mandibular fixation), presence of concomitant injuries (poly-traumatized patient), and condition of the case at discharge time.

\section{Statistical analysis}

Results were expressed as frequency and percent for categorical variables and mean $\pm \mathrm{SD}$ for continuous variables. Chi-square test $\left(\chi^{2}\right)$ was used for comparing proportions between the different etiological causes of maxillofacial injuries regarding age and gender. $p$ value $<0.05$ was considered statistically significant.

\section{Ethics considerations}

Ethical approval was obtained from the Ethical Committee of Faculty of Medicine, Assiut University, Egypt. Consent to participate from participants is not applicable as the data was obtained from the electronic health database.

\section{Results}

The descriptive hospital-based study includes 1221 cases of maxillofacial fractures with a closed head injury that attended the Trauma Unit of Assiut University Hospitals, Egypt, between January 2011 and December 2016. The percent of maxillofacial fractures was $4 \%$ (total number of trauma cases admitted to the trauma unit was 30,525).

Regarding the socio-demographic characteristics of the studied population, the highest percent of maxillofacial fractures (MFF) was among the age group 18-40 years $(49.2 \%)$ followed by the age group $<18$ years $(34 \%)$ and the age group $\geq 40$ years $(16.8 \%$ ); mean age was $25.9 \pm$ 15.3 years and range of age from 1 year (youngest age group) to 90 years (oldest age group). Regarding the gender of cases with MFF, males represent $88 \%$ of cases; male to female ratio was about $7: 1 ; 59.6 \%$ of the cases belonged to the urban area while $40.4 \%$ were from rural areas. More than half of the cases were unemployed (54.6\%), 33.8\% were workers, and $11.6 \%$ were employers (Fig. 1).

Table 1 showed the medico-legal criteria and revealed that road traffic accidents were the main etiology of injury (69.7\%), followed by falls (fall from height and on the ground, 15.1\%) and violent assaults and fight (10.2\%) while firearm injuries were the least etiology (5\%). Accidental manner of injury was the commonest in more than four fifths of the cases $(83.1 \%)$ followed by the homicidal manner in less than one fifth of the injuries (16.3\%); only seven cases were due to suicidal attack. Different patterns of maxillofacial fractures were present as mandibular fracture was the commonest one (49.7\%) followed by fracture maxilla (19.2\%), then fracture zygoma (16.8\%), and lastly frontal bone fracture and nasal and naso-ethmoid fracture $(9.1 \%$ and $5.2 \%)$ respectively.

The clinical profile of combined maxillofacial with closed head injury fracture cases was as follows: about half of the cases $(50.7 \%)$ had mild traumatic head injury (THI) (GCS was 12:15), 46.0\% were of moderate THI (GCS 8:11), and only 3.3\% of the cases had severed THI (GCS less than 8). Treatment of maxillofacial fracture was conservative in $50.0 \%$ of the cases and surgical in the remaining half. Treatment modalities in the form of arch bar were indicated in 30.7\%, not indicated in $35.8 \%$ of the cases; mandibular fixation was indicated in 3.3\%, not indicated in $63.2 \%$ of the cases; $33.5 \%$ of the cases were discharged on-demand or died before evaluation for intervention; the final fate of the cases was improvement in $63.0 \%$. Only $10.3 \%$ refuse surgery and $10.1 \%$ referred to private clinic on-demand after clinical and radiological evaluation, with a case fatality rate of $16.6 \%$. Isolated maxillofacial fractures were in $10.9 \%$ while polytrauma was present in $89.1 \%$ (Table 2).

There is a statistically significant difference between the etiology of craniomaxillofacial fractures and age distribution ( $p$ value $<0.001$ ); road traffic injuries occurred most in age $18 \leq 40$ years $(76.2 \%)$ compared with $62.7 \%$ and $64.9 \%$ in the age group $<18$ and $\geq 40$ years, respectively. Fall from height/on the ground occurred most in age $<18$ years $(29.2 \%)$. Violent assaults/fights and firearm injuries occurred most in age $\geq 40$ years $(15.6 \%$ and $7.3 \%$, respectively) (Fig. 2).

Figure 3 reveals a statistically significant difference between the etiology of craniomaxillofacial fractures and gender of cases ( $p$ value $<0.001$ ); road traffic injuries and violent assaults/fights occurred mostly in males (76.2\% and $10.9 \%$, respectively) compared with females (47.9\% and 5.5\%, respectively). However, fall from height/on the ground occurred most in females (41.8\%).

Figure 4 reveals that all motor car accidents were unintentional and falls from heights were responsible for all suicidal cases with MF fractures. Violent assaults were the usual homicidal manner as a general way of assault; firearm injuries were homicidally inflicted in about one fourth of the cases.

Concerning the trend of occurrence of maxillofacial fractures and its different patterns from the year 2011 to 2016, the proportion tended to be increasing with the 


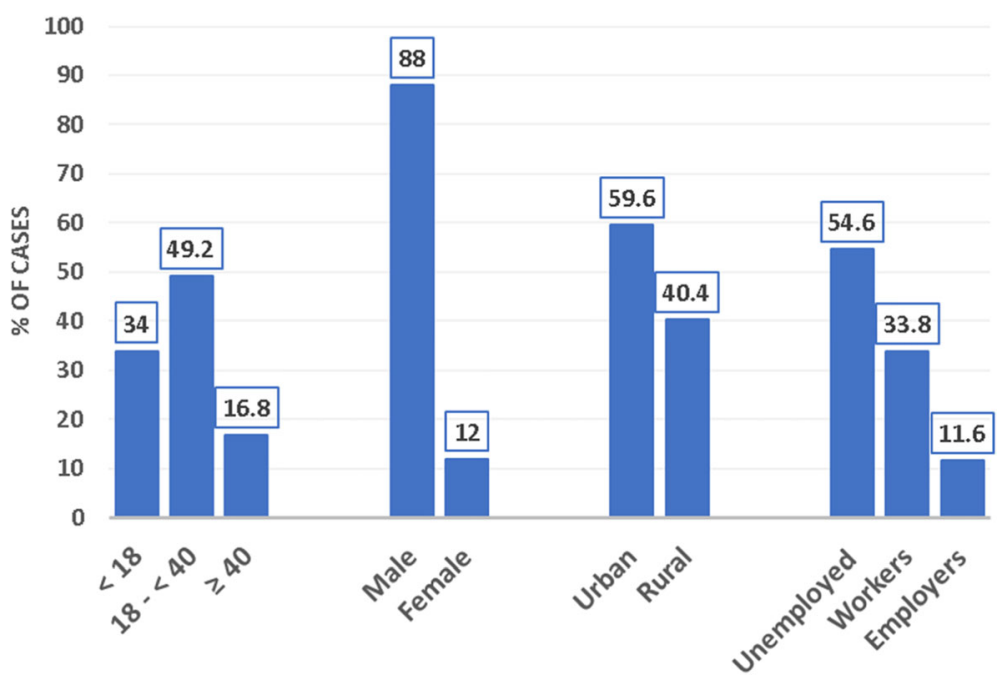

Fig. 1 Socio-demographic characteristics of combined craniomaxillofacial fracture cases in the studied period (2011-2016)

highest incidence in 2011 (21.5\%) and the lowest in 2014 (16.5\%), with more or less steady trend between 2011 and 2014 and fluctuating trend between 2014 and 2016. Regarding the different pattern of MFF, mandibular fracture has the highest incidence of occurrence (49.7\%) with a trend followed the maxillofacial fractures trend (Fig. 5).

\section{Discussion}

Traumatic injury is the most common cause of death in the last 10 years and still a significant health problem in

Table 1 Medico-legal aspects of craniomaxillofacial fracture cases in the studied period (2011-2016)

\begin{tabular}{lll}
\hline Variables & Cases \\
\cline { 3 - 3 } & No. $=1221$ & $\%$ \\
\hline Etiology of MF fractures & 851 & 69.7 \\
Road traffic injuries ${ }^{*}$ & 184 & 15.1 \\
Fall from height and on the ground & 125 & 10.2 \\
Violent assault and fight & 61 & 5.0 \\
Firearm injuries & & \\
Manner of MF fracture & 1015 & 83.1 \\
Accidental & 199 & 16.3 \\
Homicidal & 7 & 0.6 \\
Suicidal & & \\
Pattern of MF fracture & 607 & 49.7 \\
Mandibular fracture & 234 & 19.2 \\
Fracture maxilla & 205 & 16.8 \\
Fracture zygoma & 111 & 9.1 \\
Frontal bone fracture & 64 & 5.2 \\
Nasal and naso-ethmoid fracture & & \\
\hline \#Road traffic injuries include motor car motorcycle and train accidents &
\end{tabular}

\#Road traffic injuries include motor car, motorcycle, and train accidents all countries, in spite of the level of the socio-economic state. About 12,000 Egyptians died each year due to different types and etiological causes of trauma (El Shehaby et al. 2018). The human face often constitutes the first point of contact in various human interactions and is frequently the preferred target for blows in assault cases (El Shehaby et al. 2019). Maxillofacial trauma is thus a common presentation in accident and emergency departments either as an isolated injury or as a part of poly-trauma. These injuries may cause serious functional, psychological, physical, and cosmetic disabilities (Kapoor and Kalra 2012).

The present study is a descriptive hospital-based study that was carried out on 1221 trauma patients with maxillofacial fractures combined with closed head injury of both sexes referred to the Trauma Unit and Maxillofacial Surgery Department of Assiut University Hospitals (tertiary care hospital), Egypt, throughout the period from 1 January 2011 to the end of December 2016.

The epidemiological criteria revealed that maxillofacial fractures accounted for $4 \%$ of all trauma cases, and its peak was at the year 2011 and 2015; this result is slightly higher than that reported by Pillay et al. which reported the incidence of craniomaxillofacial fractures as $2.9 \%$ (Pillay et al. 2018), but lower than that previously reported (16\%) in a similar study conducted in Australia (Shahim et al. 2006). The incidence of traumatic head injury (THI) associated with MFF in different countries around the world is greatly different, but the overall result is higher in males when compared with females; in the present study, it is 7:1; this result is in accordance with Patil et al. (2016). Other studies in the developed countries, the male/female ratio ranged from $2: 1$ to $4: 1$, which indicates the active participation of women in outdoor life activities than in developing countries (Gassner et al. 2003). 
Table 2 Clinical profile of craniomaxillofacial fracture cases in the studied period (2011-2016)

\begin{tabular}{|c|c|c|}
\hline \multirow[t]{2}{*}{ Variables } & \multicolumn{2}{|l|}{ Cases } \\
\hline & No. $=1221$ & $\%$ \\
\hline \multicolumn{3}{|l|}{ Glasgow Coma Scale (GCS) } \\
\hline Mild & 619 & 50.7 \\
\hline Moderate & 562 & 46.0 \\
\hline Severe & 40 & 3.3 \\
\hline \multicolumn{3}{|l|}{ Type of treatment } \\
\hline Conservative & 610 & 50.0 \\
\hline Surgical & 611 & 50.0 \\
\hline \multicolumn{3}{|l|}{ Treatment modalities } \\
\hline \multicolumn{3}{|l|}{ Arch bar } \\
\hline Indicated arch bar & 375 & 30.7 \\
\hline Not indicated arch bar & 437 & 35.8 \\
\hline Death, escape, and discharge on-demand before evaluation on intervention & 409 & 33.5 \\
\hline \multicolumn{3}{|l|}{ Mandibular fixation } \\
\hline Indicated & 40 & 3.3 \\
\hline Not indicated & 772 & 63.2 \\
\hline Death, escape, and discharge on-demand before intervention & 409 & 33.5 \\
\hline \multicolumn{3}{|l|}{ Condition of the case on discharge } \\
\hline Improved & 769 & 63.0 \\
\hline Refuse surgery & 126 & 10.3 \\
\hline Referred to a private clinic on demand & 123 & 10.1 \\
\hline Death & 203 & 16.6 \\
\hline \multicolumn{3}{|l|}{ Associated injuries } \\
\hline Isolated craniomaxillofacial fracture & 133 & 10.9 \\
\hline Poly-traumatized patients & 1088 & 89.1 \\
\hline
\end{tabular}

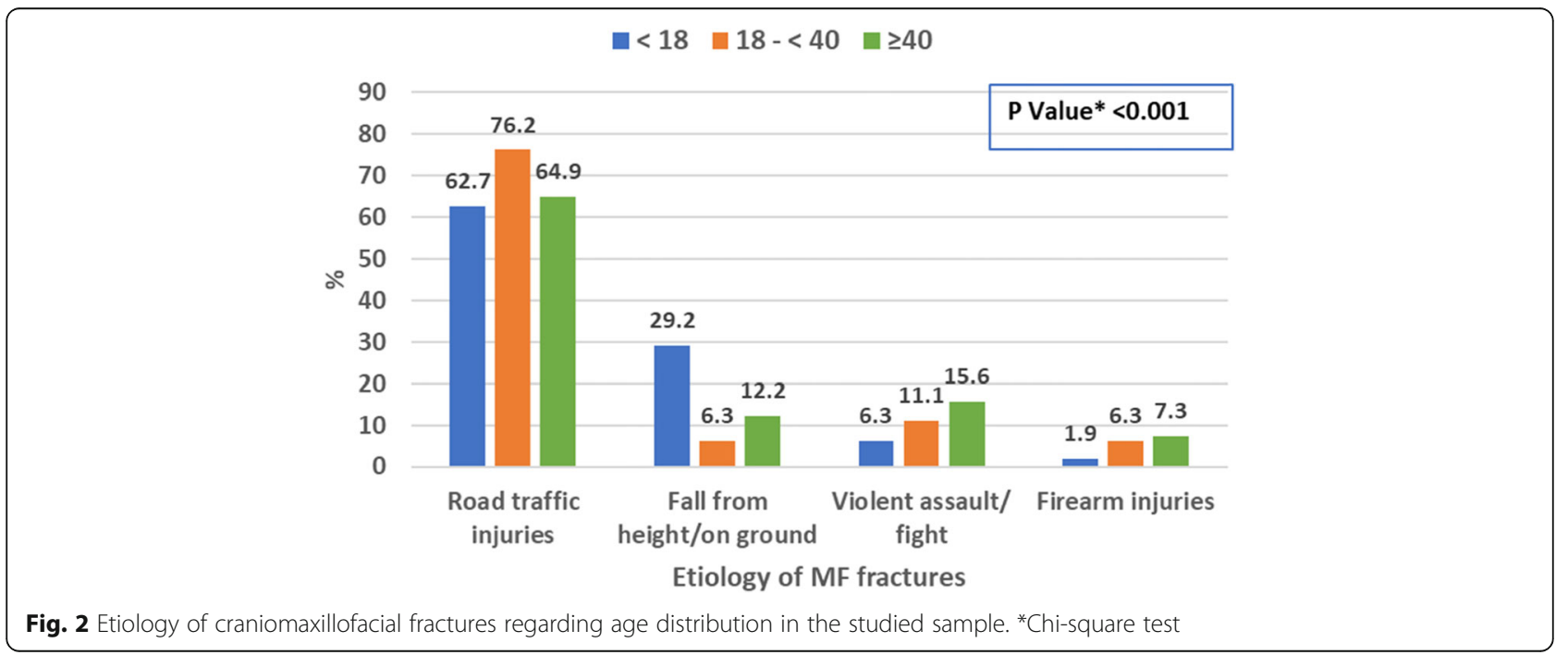




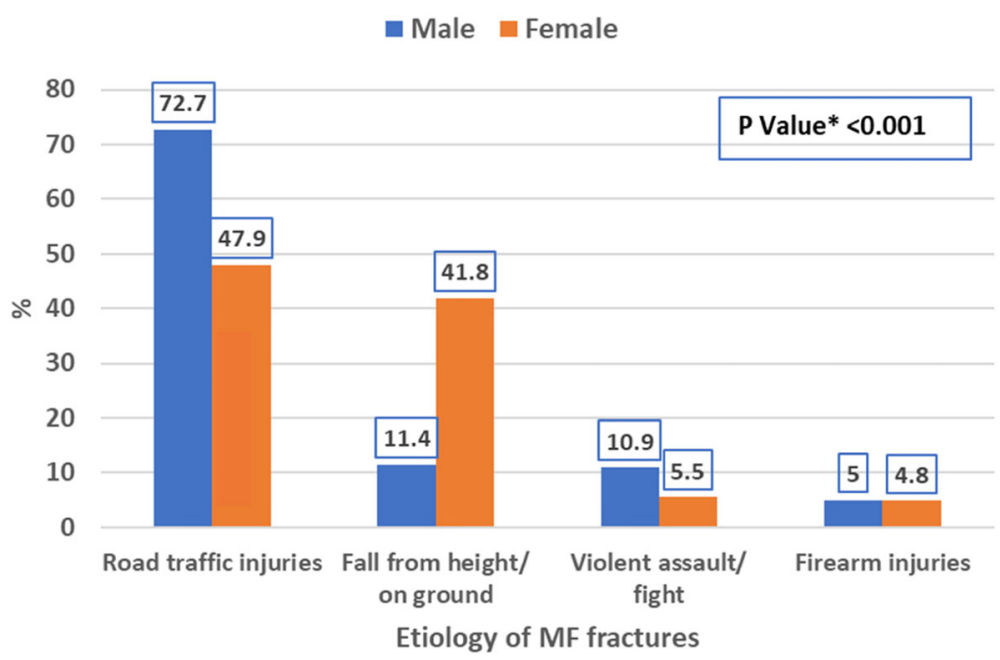

Fig. 3 Etiology of craniomaxillofacial fractures regarding gender in the studied sample. ${ }^{*}$ Chi-square test

Considerable variations between developing and developed countries may be present but still male outnumber female by more than 2 to 1 ; this may be attributed to the higher percentage of women in developed countries who participate directly in economic, social, and cultural activities, and therefore, they are consequently susceptible to violence, traffic accidents, and sports accident (El Shehaby et al. 2018). Men usually outnumber women in developing countries due to their mobility, more frequently involved in stronger physical, violent activities, and motor vehicle crashes and often sustain more severe injuries compared with females (El Shehaby et al. 2019). In the present study, the commonest age group among the injured cases was $18-40$ years; it was suggested that this is the age of adolescence and adulthood where persons frequently carelessly drive motor vehicles and practice dangerous exercises and thus exposing themselves to all types of violent trauma (Thorén et al. 2010). This agrees with the result of Mijiti et al. (2014) that showed most cases exposed to THI concomitant with MFF are men between 20 and 39 years.

The main etiology for craniomaxillofacial fractures over the reported 6-year period was road traffic accidents $(69.7 \%)$; this finding is supported by several studies where traffic accidents were the most prevalent etiology of facial trauma (Samieirad et al. 2015). The second etiology was fall then followed by interpersonal violence which was the third responsible etiological cause; this result is similar to Sbordone et al. 2018. Alternatively, other recent metacentric retrospective studies from Southern Italy in 2018 reported that the vast majority of cases were due to violent assaults followed by road traffic accident (RTA) then falls (Khan and Arif 2005). Road traffic accident is the leading cause of traumatic injuries in developing countries, while interpersonal violence is the leading cause in developed countries (Pillay et al.

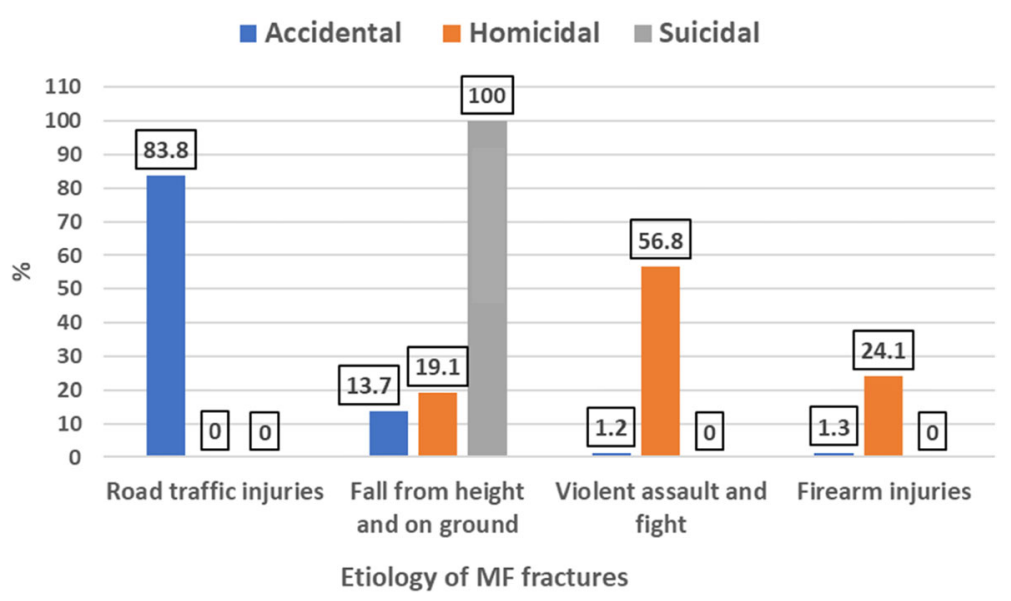

Fig. 4 Etiology of craniomaxillofacial fractures according to the manner of fracture infliction in the studied sample 


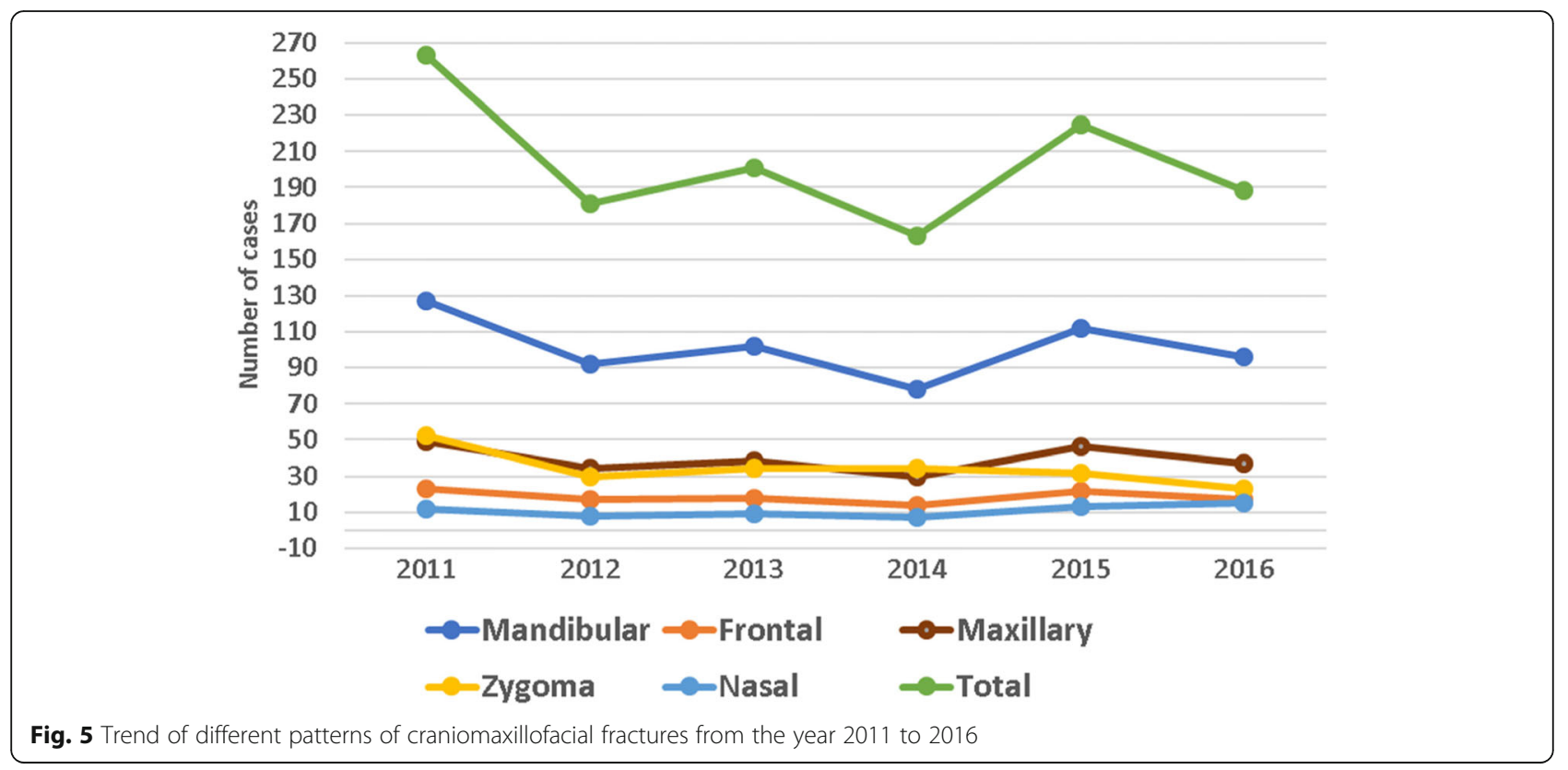

2018). The possible causes for this in Egypt are multifactorial that may be due to bad road conditions and poor road lighting along with lack of adequate public transport systems all contribute to increased trauma. The primary reasons for the increase in fatalities and injuries from traffic crashes in developing countries are simply the rising number of motor vehicles, economic growth associated with increased mobility, need to travel for employment, lack of traffic police manpower to implement existing laws, sudden urbanization as well as availability of easy loans for middle and low socio-economic population, and lack of awareness of the use of helmets. These findings should announce the need for better road traffic awareness among masses (Fasola et al. 2003).

Falls in the form of fall from heights and fall on the ground are considered as persistent hazards met in all communities and occupational settings. It is frequently encountered in accidents, suicides, and rarely in homicides (Hagga et al. 2016). The extent of injuries sustained due to fall from heights varies depending on the falling height, composition of the impact surface, intermediate objects encountered during the fall process, rate of deceleration, position of the body on landing, and individual factors such as age, body weight, preexisting disease, and also age of the person (child, adult, elderly). In the case of falls, craniocerebral trauma (head injury) is the primary cause of mortality among skeletal injuries. Among soft tissue injuries, injury to the brain followed by the liver, lung, and spleen was frequent (Sasaki et al. 2009).

Injuries are caused by intentional and unintentional causes; intentional injuries occur with purposeful intent and include homicide, suicide, domestic violence, sexual assaults, bias-related violence, and firearms. Unintentional injuries are injuries that occur without purposeful intent (Sasaki et al. 2009). In the present study, accidental manner of injury was a major manner of craniomaxillofacial fractures followed by homicidal manner, while suicidal attack represents less than $1 \%$ only; this can be explained by the fact that road traffic accidents (as a major responsible for accidental manner) outnumbered interpersonal violence.

In agreement with some studies (Kapoor and Kalra 2012; van den Bergh et al. 2012), mandibular fracture constitutes a major portion of maxillofacial fractures (49.7\%) because of its prominence and unique mobility, and though a very strong bone, mandible has several areas of weaknesses, followed by fracture maxilla (19.2\%), then fracture zygoma (16.8\%), and lastly frontal bone and ethmoid fractures $(9.1 \%$ and $5.2 \%$, respectively). Zygoma was found to be the main bone involved in the maxillofacial region in Bajwa et al. (2012) while the maxilla and nasal bones to be the main bones involved in maxillofacial trauma in Haug et al. (1992).

The Glasgow Coma Scale (GCS) is a reliable tool for the evaluation of mental status, potential brain injury, clinical conditions, and prognosis of the traumatized patients on admission in the emergency department (Majdan et al. 2015). The GCS provides a reproducible index of neurologic status based on numerical values that are ascribed to eye-opening, best verbal response, and best motor response. However, it is not a substitute for a detailed neurologic examination (Vrinceanu and Banica 2014). On the basis of GCS scores of the patients, 
about half of the cases (50.7\%) had mild THI, 46.0\% were of moderate THI, and only $3.3 \%$ of the cases had severed THI. The high incidence of a mild type of head injuries associated with maxillofacial injuries is in agreement with Hasnat et al. (2017). However, another study showed a significantly greater incidence of moderate type of head injuries associated with maxillofacial injuries (Senthilkumar et al. 2017).

Oral and maxillofacial surgeons who undertake treatment of facial injuries should have the responsibility for repair of the aesthetic defect, restoration of function, and reduction of the period of disability. The choice for treatment concepts in the current study is $50 \%$ were treated surgically and $50 \%$ of cases were treated conservatively in the university hospital. However, another study reported a higher percentage of cases treated surgically (66.08\%) (Vrinceanu and Banica 2014). Approaches to the craniomaxillofacial fractures were according to the clinical guidelines including nondisplaced fractures were managed conservatively with providing acceptable functional and esthetic results, displaced fractures were managed surgically by open reduction (repositioning of the displaced segments into anatomic position), and rigid internal fixation with mini plates (Perry 2010; Hailemichael et al. 2015).

There was a significant statistical association between age and etiology of MFF (RTA, falls, violence, and firearm injuries) $(p<0.05)$; the higher occurrence of RTA among males than females ( $72.7 \%$ males, $47.9 \%$ females) while falls were the main etiology among women $(41.8 \%$ in female, $11.4 \%$ in male) as reported in previous studies (Chalya et al. 2011) because more men than women are commuting.

The trend of maxillofacial fractures and its different patterns from the year 2011 to 2016 were the highest in 2011 (21.5\%) (the year of 25th January Revolution); this can be explained by that the 25th January Revolution aroused some political conflicts and members of different political groups that used violence and aggressive behavior to express their opinions in political struggles subsequently increased the frequency of violent assaults and the trauma incidence in general, while in the year of 2014, the Egyptian community retained its political stability and the police forces retained its control ability of violence with marked restriction in the violent assaults and fights (El Shehaby et al. 2018).

\section{Recommendation}

Preventive strategies remain the cheapest way to reduce the direct and indirect costs of the trauma sequelae. Improving vehicle safety and stricter laws is equally important. Early availability of backup services like intensive care unit and interventions from the trauma team improves the institution of trauma registry regarding the epidemiology, patterns, treatment modalities, and longrun complications of craniomaxillofacial fractures as well as an analysis of data on a regular basis to understand the trends and assess the impact of interventions for the improvement of care and lowering the morbidity. Conduction of prospective studies with follows up to record the actual end results of such traumas.

\section{Conclusion}

Maxillofacial fracture is a common injury presenting to the emergency department. Maxillofacial fractures concomitant with closed head injuries in Upper Egypt occurred primarily in men aged $18 \leq 40$ years with male predominance. A road traffic accident is the main etiologic factor, and mandibular fractures are the commonest pattern followed by fracture maxilla. Traumatic head injuries were mild in half of the cases. The trend of maxillofacial fractures over the 6-year period of the study (2011-2016) tended to be increased with the highest number in 2011 while the lowest in 2014.

\section{Abbreviations \\ CHI: Closed head injury; CT: Computerized tomography; GCS: Glasgow Coma Scale; MFF: Maxillofacial fractures; RTA: Road traffic accident; THI: Traumatic head injury}

\section{Acknowledgements \\ The author wishes to acknowledge Dr. Mahmoud Ali Ragaey, Lecturer of Ear, Nose, and Throat (ENT), Faculty of Medicine, Assiut University, Assiut, Egypt, for his help in facilitating and obtaining the required data from the electronic health datasheet.}

\section{Authors' contributions}

DMES conceived the idea of the study, designed the protocol, obtained the ethical approval from the Ethical Committee, wrote the manuscript and discussion sections, supervised the participation in the research items, and revised all writing steps. HMM designed the study methods, statistical cleaning, and analysis; revised the discussion section; and arranged the reference on the endnote program. Both DMES and HMM are the guarantors of this manuscript and responsible for the interpretation of study results as well as writing of the final manuscript. AMAF participated in the writing of the discussion section. MSS facilitated in obtaining the data from the registration office of the Trauma Unit of Assiut University Hospitals. All authors read and approved the final manuscript.

\section{Funding}

The author received no funding for this work.

\section{Availability of data and materials \\ Not available}

\section{Ethics approval and consent to participate}

Ethical approval is obtained from the Ethical Committee of Faculty of Medicine, Assiut University, Egypt.

Consent to participate from participants is not applicable as the data was obtained from the electronic health database.

Consent for publication

Not applicable

Competing interests

The authors declare that they have no competing interests. 


\section{Author details}

'Department of Forensic Medicine \& Clinical Toxicology, Faculty of Medicine, Assiut University, Asyut 71515, Egypt. ²Department of Forensic Medicine \& Clinical Toxicology, Faculty of Medicine, Al-Azher University, Asyut, Egypt. ${ }^{3}$ Maxillo-facial Surgery Unit of General Surgery Department, Faculty of Medicine, Assiut University, Asyut, Egypt. ${ }^{4}$ Department of Public Health \& Community Medicine, Faculty of Medicine, Assiut University, Asyut, Egypt.

Received: 16 September 2019 Accepted: 20 January 2020

Published online: 05 March 2020

\section{References}

Bajwa S, Kaur J, Singh A, Kapoor V, Bindra G, Ghai G (2012) Clinical and critical care concerns of cranio-facial trauma: a retrospective study in a tertiary care institute. National Journal of Maxillofacial Surgery 3(2):133-138

Chalya PL, Mchembe M, Mabula JB, Kanumba ES, Gilyoma JM (2011) Etiological spectrum, injury characteristics and treatment outcome of maxillofacial injuries in a Tanzanian teaching hospital. Journal of Trauma Management, Outcomes 5(1):7

Delpachitra S, Rahmel B (2016) Orbital fractures in the emergency department: a review of early assessment and management. Emerg Med J 33(10):727-731

El Shehaby D, Saleh M, Shahine M, Sayed MM (2018) Did January 25th Egyptian revolution change the medico-legal pattern and the trend of hospitalized injuries in Upper Egypt? A retrospective study. The Egyptian Journal of Forensic Sciences and Applied Toxicology 18(4):15-27

El Shehaby DM, Ragaey MA, Omeran GA (2019) Medico-legal aspects of otorhinolaryngeal, face and neck injuries in Upper Egypt: a prospective analysis and retrospective evaluation of claimed disabilities. The Egyptian Journal of Forensic Science and Applied Toxicology 19(3):103-120

Fama F, Cicciu M, Sindoni A, Nastro-Siniscalchi E, Falzea R, Cervino G, Polito F, De Ponte F, Gioffre-Florio M (2017) Maxillofacial and concomitant serious injuries: an eight-year single center experience. Chin J Traumatol 20(1):4-8

Fasola AO, Nyako EA, Obiechina AE, Arotiba JT (2003) Trends in the characteristics of maxillofacial fractures in Nigeria. J Oral Maxillofac Surg 61(10):1140-1143

Gassner R, Tuli T, Hächl O, Rudisch A, Ulmer H (2003) Cranio-maxillofacial trauma: a 10 year review of 9543 cases with 21,067 injuries. J CranioMaxillofac Surg 31(1):51-61

Hagga GO, Zamzam S, Sharaf Eldin AA, Madboly GA (2016) Pattern of fatal injuries of fall from height at Great Cairo: a retrospective analytical study (2009-2013) Egypt. The Egyptian Journal of Forensic Sciences and Applied Toxicology 16(2):97-116

Hailemichael F, Suleiman M, Pauolos W (2015) Magnitude and outcomes of road traffic accidents at hospitals in Wolaita Zone, SNNPR, Ethiopia. BMC Research Notes 8(1):135

Hasnat A, Hoque AE, Azam MSU, Kamrujjaman M, Akhtar M (2017) Pattern of maxillofacial trauma among patients with head injuries. Update Dental College Journal 7(1):14-20

Haug RH, Savage JD, Likavec MJ, Conforti PJ (1992) A review of 100 closed head injuries associated with facial fractures. J Oral Maxillofac Surg 50(3):218-222

Kapoor P, Kalra N (2012) A retrospective analysis of maxillofacial injuries in patients reporting to a tertiary care hospital in East Delhi. International Journal of Critical IIIness and Injury Science 2(1):6

Khan AR, Arif S (2005) Ear nose and throat injuries in children. Journal of Ayub Medical College Abbottabad 17(1):54-56

Kloss F, Laimer K, Hohlrieder M, Ulmer H, Hackl W, Benzer A, Schmutzhard E, Gassner R (2008) Traumatic intracranial haemorrhage in conscious patients with facial fractures-a review of 1959 cases. J Cranio-Maxillofac Surg 36(7): 372-377

Majdan M, Steyerberg EW, Nieboer D, Mauritz W, Rusnak M, Lingsma HF (2015) Glasgow coma scale motor score and pupillary reaction to predict six-month mortality in patients with traumatic brain injury: comparison of field and admission assessment. J Neurotrauma 32(2):101-108

Mijiti A, Ling W, Tuerdi M, Maimaiti A, Tuerxun J, Tao YZ, Saimaiti A, Moming A (2014) Epidemiological analysis of maxillofacial fractures treated at a university hospital, Xinjiang, China: a 5-year retrospective study. J CranioMaxillofac Surg 42(3):227-233

Motamedi MHK (2003) An assessment of maxillofacial fractures: a 5-year study of 237 patients. J Oral Maxillofac Surg 61(1):61-64
Parashar A, Sharma RK (2013) Unfavourable outcomes in maxillofacial injuries: how to avoid and manage. Indian Journal of Plastic Surgery: official publication of the Association of Plastic Surgeons of India 46(2):221-234

Patil SG, Patil BS, Joshi U, Allurkar S, Japatti S, Munnangi A (2016) The facial skeleton: armor to the brain? Indian Journal of Dentistry 7(3):116

Perry M (2010) Developments and controversies in maxillofacial trauma: repair of facial injuries. Faculty Dental Journal 1(1):20-25

Pillay L, Mabongo M, Buch B (2018) Prevalence and aetiological factors of maxillofacial trauma in a rural district hospital in the eastern cape. South African Dental Journal 73(5):348-353

Samieirad S, Tohidi E, Shahidi-Payam A, Hashemipour M-A, Abedini A (2015) Retrospective study maxillofacial fractures epidemiology and treatment plans in Southeast of Iran. Med Oral Patol Oral Cir Bucal 20(6):e729-e736

Sasaki R, Ogiuchi H, Kumasaka A, Ando T, Nakamura K, Ueki T, Okada Y, Asanami S, Chigono Y, Ichinokawa Y (2009) Analysis of the pattern of maxillofacial fracture by five departments in Tokyo. Oral Science International 6(1):1-7

Sbordone C, Barca I, Petrocelli M, Orabona GDA, Vaira LA, Colangeli W, Cristofaro MG, Giudice M, Giudice A, Cassandro FM (2018) The influence of socioeconomic factors on the epidemiology of maxillofacial fractures in Southern Italy. Journal of Craniofacial Surgery 29(8):2119-2123

Senthilkumar R, Kavitha AP, Anandan H (2017) Analysis of the outcome of mandible fracture management. International Journal of Scientific Study 5(3)

Shahim FN, Cameron P, McNeil JJ (2006) Maxillofacial trauma in major trauma patients. Aust Dent J 51(3):225-230

Syed A, Lone N, Wani MA, Bhat A (2007) Clinical management of patients with minor head injuries. Int J Health Sci 1(1):131-140

Thorén H, Snäll J, Salo J, Suominen-Taipale L, Kormi E, Lindqvist C, Törnwall J (2010) Occurrence and types of associated injuries in patients with fractures of the facial bones. J Oral Maxillofac Surg 68(4):805-810

van den Bergh B, Karagozoglu KH, Heymans MW, Forouzanfar T (2012) Aetiology and incidence of maxillofacial trauma in Amsterdam: a retrospective analysis of 579 patients. J Cranio-Maxillofac Surg 40(6):e165-e169

Vrinceanu D, Banica B (2014) Principles of surgical treatment in the midface trauma-theory and practice. Maedica 9(4):361-366

Zandi M, Hoseini SRS (2013) The relationship between head injury and facial trauma: a case-control study. J Oral Maxillofac Surg 17(3):201-207

\section{Publisher's Note}

Springer Nature remains neutral with regard to jurisdictional claims in published maps and institutional affiliations.

\section{Submit your manuscript to a SpringerOpen ${ }^{\circ}$ journal and benefit from:}

- Convenient online submission

- Rigorous peer review

- Open access: articles freely available online

- High visibility within the field

- Retaining the copyright to your article

Submit your next manuscript at $>$ springeropen.com 